
"To Open Minds, To Educate Intelligence, To Inform Decisions"

The International Academic Forum provides new perspectives to the thought-leaders and decision-makers of today and tomorrow by offering constructive environments for dialogue and interchange at the intersections of nation, culture, and discipline. Headquartered in Nagoya, Japan, and registered as a Non-Profit Organization (一般社 団法人) , IAFOR is an independent think tank committed to the deeper understanding of contemporary geo-political transformation, particularly in the Asia Pacific Region.

\section{INTERNATIONAL \\ INTERCULTURAL \\ INTERDISCIPLINARY}

iafor 



\section{The Executive Council of the International Advisory Board}

\section{Mr Mitsumasa Aoyama}

Director, The Yufuku Gallery, Tokyo, Japan

\section{Lord Charles Bruce}

Lord Lieutenant of Fife

Chairman of the Patrons of the National Galleries of Scotland

Trustee of the Historic Scotland Foundation, UK

\section{Professor Donald E. Hall}

Herbert J. and Ann L. Siegel Dean

Lehigh University, USA

Former Jackson Distinguished Professor of English and Chair of the Department of English

\section{Professor Arthur Stockwin}

Founding Director of the Nissan Institute for Japanese Studies \& Emeritus Professor The University of Oxford UK

\section{Professor Chung-Ying Cheng}

Professor of Philosophy, University of Hawaili at Manoa, USA

Editor-in-Chief, The Journal of Chinese Philosophy

\section{Professor Steve Cornwell}

Professor of English and Interdisciplinary Studies, Osaka Jogakuin University, Osaka, Japan

Osaka Local Conference Chair

\section{Professor A. Robert Lee}

Former Professor of English at Nihon University, Tokyo from 1997 to 201 I, previously long taught at the University of Kent at Canterbury, UK

\section{Professor Dexter Da Silva}

Professor of Educational Psychology, Keisen University, Tokyo, Japan

\section{Professor Georges Depeyrot}

Professor and Director of Research \& Member of the Board of Trustees

French National Center for Scientific Research (CNRS) \& L'Ecole Normale Superieure, Paris, France

\section{Professor Johannes Moenius}

William R. and S. Sue Johnson Endowed Chair of Spatial Economic Analysis and Regional Planning The University of Redlands School of Business, USA

\section{Professor June Henton}

Dean, College of Human Sciences, Auburn University, USA

\section{Professor Michael Hudson}

President of The Institute for the Study of Long-Term Economic Trends (ISLET)

Distinguished Research Professor of Economics, The University of Missouri, Kansas City

\section{Professor Koichi Iwabuchi}

Professor of Media and Cultural Studies \& Director of the Monash Asia Institute, Monash University, Australia

\section{Professor Sue Jackson}

Professor of Lifelong Learning and Gender \& Pro-Vice Master of Teaching and Learning, Birkbeck, University of London, UK

\section{Professor Sir Geoffrey Lloyd}

Senior Scholar in Residence, The Needham Research Institute, Cambridge, UK

Fellow and Former Master, Darwin College, University of Cambridge

Fellow of the British Academy

Professor Keith Miller

Orthwein Endowed Professor for Lifelong Learning in the Science, University of Missouri-St.Louis, USA

\section{Professor Kuniko Miyanaga}

Director, Human Potential Institute, Japan

Fellow, Reischauer Institute, Harvard University, USA

\section{Professor Dennis Mclnerney}

Chair Professor of Educational Psychology and CoDirector of the Assessment Research Centre The Hong Kong Institute of Education, Hong Kong SAR

\section{Professor Brian Daizen Victoria}

Professor of English

Fellow of the Oxford Centre for Buddhist Studies

\section{Professor Michiko Nakano}

Professor of English \& Director of the Distance Learning Center, Waseda University, Tokyo, Japan

Professor Thomas Brian Mooney

Professor of Philosophy

Head of School of Creative Arts and Humanities Professor of Philosophy and Head of School of Creative Arts and Humanities, Charles Darwin University, Australia

\section{Professor Baden Offord}

Professor of Cultural Studies and Human Rights \& CoDirector of the Centre for Peace and Social Justice Southern Cross University, Australia

Professor Frank S. Ravitch

Professor of Law \& Walter H. Stowers Chair in Law and Religion, Michigan State University College of Law

\section{Professor Richard Roth}

Senior Associate Dean, Medill School of Journalism,

Northwestern University, Qatar

Professor Monty P. Satiadarma

Clinical Psychologist and Lecturer in Psychology \&

Former Dean of the Department of Psychology and Rector of the University, Tarumanugara University, Indonesia

\section{Mr Mohamed Salaheen}

Director, The United Nations World Food Programme, Japan \& Korea

\section{Mr Lowell Sheppard \\ Asia Pacific Director, HOPE International}

Development Agency, Canada/Japan

His Excellency Dr Drago Stambuk

Croatian Ambassador to Brazil, Brazil

\section{Professor Mary Stuart}

Vice-Chancellor,The University of Lincoln, UK

\section{Professor Gary Swanson}

Distinguished Journalist-in-Residence \& Mildred S.

Hansen Endowed Chair, The University of Northern Colorado, USA

\section{Professor Jiro Takai}

Secretary General of the Asian Association for Social Psychology \& Professor of Social Psychology Graduate School of Education and Human

Development, Nagoya University, Japan

Professor Svetlana Ter Minasova

President of the Faculty of Foreign Languages and

Area Studies, Lomonosov Moscow State University

\section{Professor Yozo Yokota}

Director of the Center for Human Rights Affairs, Japan Former UN Special Rapporteur on Myanmar

\section{Professor Kensaku Yoshida}

Professor of English \& Director of the Center for the Teaching of Foreign Languages in General Education, Sophia University, Tokyo, Japan 

The Southeast Asian Conference on Education 2021

Official Conference Proceedings

ISSN: $2435-5240$

(C) The International Academic Forum 2021

The International Academic Forum (IAFOR)

Sakae 1-16-26-201

Naka Ward, Nagoya, Aichi

Japan 460-ooo8

www.iafor.org 

Using Predictive Analytics to Identify First-Year Engineering Students at Risk of Failing Engineering Physics

Low Beng Yew

Cha Cher Liang

Teoh Cheng Yong

pp. $1-11$

Preparing Teachers for Rural Schools in Indonesia: A Case Study of

Teachers' Professional Development Program

Munawwarah

pp. $13-27$

Physics Teachers' Conception of a Supportive Learning Environment

Kim P. Diate

Ivy Claire V. Mordeno

Amelia T. Buan

Elesar V. Malicoban

Neal Alfie Y. Lasta

pp. $29-41$

The Effect of Gender and Learning Styles on L2 Learners' Writing

Performance at Higher Education

Sabarun

Hamidah

Marsiah

pp. $43-53$

Technology Integration: Implication for Teachers' Professional

Development

Lian Krizzia G. Rosales

pp. $55-68$

A Within-Asia Comparison in English Language Classroom Anxiety

Hiromi Oda

Jatrifia Sinatrya

Uyun Nishar

Andrew Foong

Naoko Ichii

pp. $69-84$

Design Thinking Applied to Advertising Design Courses to Enhance

Students' Learning Achievement

Fang Ching-Jung

pp. $85-98$

Stories and Experiences in the Time of Pandemic: Online Conversations of Filipino Student Affairs and Services Practitioners

Leandro A. Loyola

pp. $99-112$

A Critical Analysis of Prevention Science Framework: An Examination of Student Discipline Programs

Diana Genevive H. Layag

pp. $113-125$ 
The Relationship between Intercultural Communication Competence and Perceived Challenges and Its Effect on the Perceived Success of

International Students in Japan

Yinghui Jia

Eunyoung Kim

pp. $127-141$

Distance Education in Hong Kong Preschools: Learning and Teaching During COVID-19 School Closures

Anika Saxena

Rebecca Smith

Aylin Kip

pp. $143-159$

Maximising Student Engagement in Online and Blended Learning:

A Survey of Learner Preferences

Arturo Molina-Cristóbal

Idris Lim

Fan Hong

Christian Della

Jolly Atit Shah

Vicki Dale

Duncan Bremner

pp. $161-170$ 


\title{
Maximising Student Engagement in Online and Blended Learning: A Survey of Learner Preferences
}

\author{
Arturo Molina-Cristóbal, University of Glasgow Singapore, Singapore \\ Idris Lim, University of Glasgow Singapore, Singapore \\ Fan Hong, University of Glasgow Singapore, Singapore \\ Christian Della, University of Glasgow Singapore, Singapore \\ Jolly Atit Shah, University of Glasgow Singapore, Singapore \\ Vicki Dale, University of Glasgow, United Kingdom \\ Duncan Bremner, University of Glasgow, United Kingdom
}

The Southeast Asian Conference on Education 2021 Official Conference Proceedings

\begin{abstract}
Blended learning is the integration of classroom face-to-face (F2F) learning with online learning experiences to engage students in a flexible learning framework. F2F lecturing is generally described as being more engaging. However, the incorporation of online resources gives students choice and flexibility in how they approach their studies and can offer an additional tool to further enhance and re-enforce content delivered F2F. Concepts of emotional and cognitive engagement and self-determination theory have attracted attention as a possible way to describe and influence student engagement in blended learning. A recent survey at the University of Glasgow Singapore (UGS) found that students perceive the incorporation of online resources favourably, with recommendations for $40-60 \%$ of teaching experiences to be video-based/online. It is important that the online content, format and delivery are designed to maximise student engagement. However, there is no consensus on the best format and balance between online work vs traditional F2F setting to achieve this outcome, and best practice guidelines are lacking. The objective of our study is to develop a series of pilot online resources across four engineering programmes and obtain student feedback through structured questionnaires, to identify what indicators and facilitators enhance engagement. In this paper, we present findings from the questionnaires on the learners' preferences and identify content and formats that are best received through online sources. In particular, our findings identify recorded video tutorials in combination with F2F lectures as a powerful tool to enhance student satisfaction and engagement.
\end{abstract}

Keywords: Student Engagement, Blended Learning

\section{iafor}

The International Academic Forum

www.iafor.org 


\section{Introduction}

\section{Blended Technologies in Learning}

Higher education institutions are faced with the challenge to modify educational experiences in tandem with the rapid progress in information technologies, as well as the expectations of prospective students for higher quality blended learning experiences. In comparison with traditional face-to-face teaching, incorporation of blended learning has the potential to provide learning opportunities that allow students to engage more deeply with their subject matter and analyse and reflect at their own pace, and should not be limited to finding a new medium to deliver old content (Garrison \& Kanuka, 2004). This move requires rethinking the teaching-learning relationship and will have profound yet uncertain implications on teaching practices and the way students engage with the university program.

Student engagement is the students' interaction with learning activities and has been identified as an indicator of student academic success and the institution's productivity (Coates, 2005b). Blended classes may make engagement more difficult for students, as they must navigate between instructional modalities, and need to be more proactive. It has been reported that several individual characteristics that make engagement in online settings difficult are: low self-efficacy, low resilience, low self-regulation. A blended learning approach may also diminish opportunities to interact, collaborate and receive feedback and social support (Manwaring et al., 2017). Given these concerns, it is essential to design the blended learning content to ensure that student engagement is considered from the beginning of its conception.

\section{Student Engagement}

Student engagement can be divided into three dimensions (Fredricks et al., 2004): (1) Behavioural engagement, it draws on the idea of participation; it includes involvement in academic and social or extracurricular activities. (2) Emotional engagement is related to positive and negative reactions to teachers, classmates, academics, and school and influence willingness to do the work. (3) Cognitive engagement is associated with willingness to exert the effort necessary to comprehend complex ideas and master difficult skills.

The three components of student engagement are interrelated within the individual and they are not an isolated processes (Fredricks et al., 2004). Park et al., (2012) argues that "students who do not feel emotionally engaged in their academic life often begin to disengage behaviourally and cognitively as well, and ultimately are at risk for poor academic outcomes". A growing body of evidence indicates that emotional engagement positively influences cognitive engagement, or otherwise put, emotional engagement precedes cognitive engagement (Fredricks et al., 2004; Manwaring et al., 2017). Therefore, an important aspect of developing online courses will be to incorporate aspects of emotional engagement to ensure that cognitive engagement is achieved.

\section{Conditions for Emotional Engagement}

Self-determination theory (SDT) by Deci \& Ryan, (1985) offers a framework for understanding the conditions under which students are likely to become emotionally engaged in their work. The SDT framework has specified a set of three psychological needs that are relevant to intrinsic motivation (Deci \& Ryan, 1994). These are: 
- $\quad$ Autonomy: the need to feel ownership of one's behaviour (choice)

- Competence: the need to produce desired outcomes and to experience mastery (confidence \& structure)

- $\quad$ Relatedness: the need to feel connected to others (social presence)

Several researchers proposed using the psychological needs specified in the SDT to identify key tenets of emotional engagement in learning (see Figure 1) (Manwaring et al., 2017; Park et al., 2012; Raes \& Depaepe, 2020; Sun \& Rueda, 2012). This approach is emerging as a promising methodology to study student engagement, and at present, there are limited studies that have measured these components of engagement with respect to specific components of the blended learning environments (e.g., videos, quizzes, lecture notes).

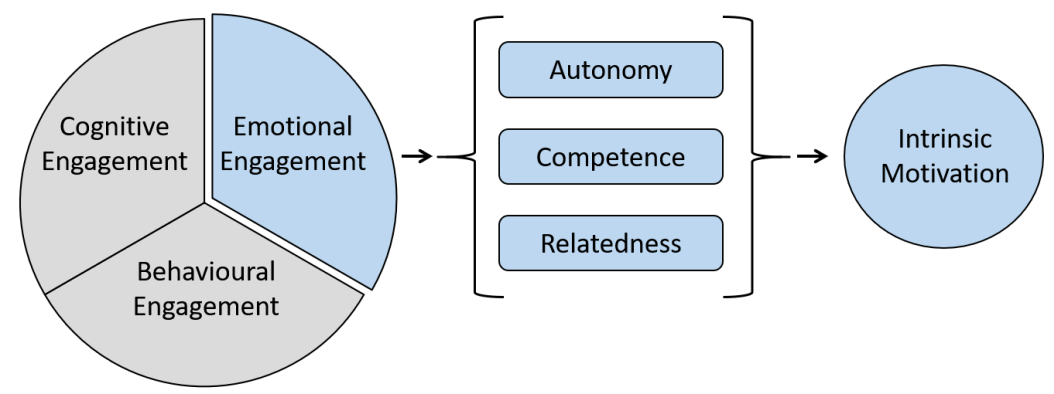

Figure 1: Dimensions of Student Engagement and Its Connection with the Self-Determination Theory Framework, Modified from (Raes \& Depaepe, 2020).

\section{Design and Review of Online Videos}

Learning management systems (LMS) platforms have become central to the delivery of blended learning in tertiary institutions (Coates, 2005a). A typical approach to designing a course is to design and upload traditional course content (e.g., lecture notes as files) to an LMS platform and make it available online for students. However, uploading content to LMS on its own is not a truly blended learning approach (Graham et al., 2013). A blended learning course should be designed such that optimally integrates face-to-face and online modes of study to engage students in a flexible learning experience.

It is not clear which format and content of the online material and the ratio of online versus F2F learning is most effective for student engagement, and best practice guidelines on how to achieve this are lacking (Delialioğlu, 2012; Manwaring et al., 2017). A qualitative study conducted at UGS by Lim Li Hong et al., (Lim Li Hong et al., 2020), which found that students were in favour of video-supplemented learning and appreciated the resulting autonomy and self-dictated pace. The majority of the students have indicated that an acceptable level of videos versus F2F lecturing is about $40-60 \%$.

Our study aims to examine the learners' preferences and identify content and formats that are best received through online sources in blended environments. We plan to develop a series of pilot online video resources across four engineering programmes and obtain student feedback through structured questionnaires, to identify what indicators (ways to measure) and facilitators (aspects of online material) enhance engagement. We present findings from some preliminary questionnaires on the learners' preferences and identify content and formats that are best received through online sources with a view to further research aimed at measuring the impact of the resources on student engagement. 


\section{Methodology}

The objective of our study is to develop a series of online resources across four engineering programs to study components of student engagement. The online resources comprise (1) F2F \& Online lectures and (2) F2F \& Online tutorials. Figure 2 shows a sample of the pilot online lectures and online tutorials.

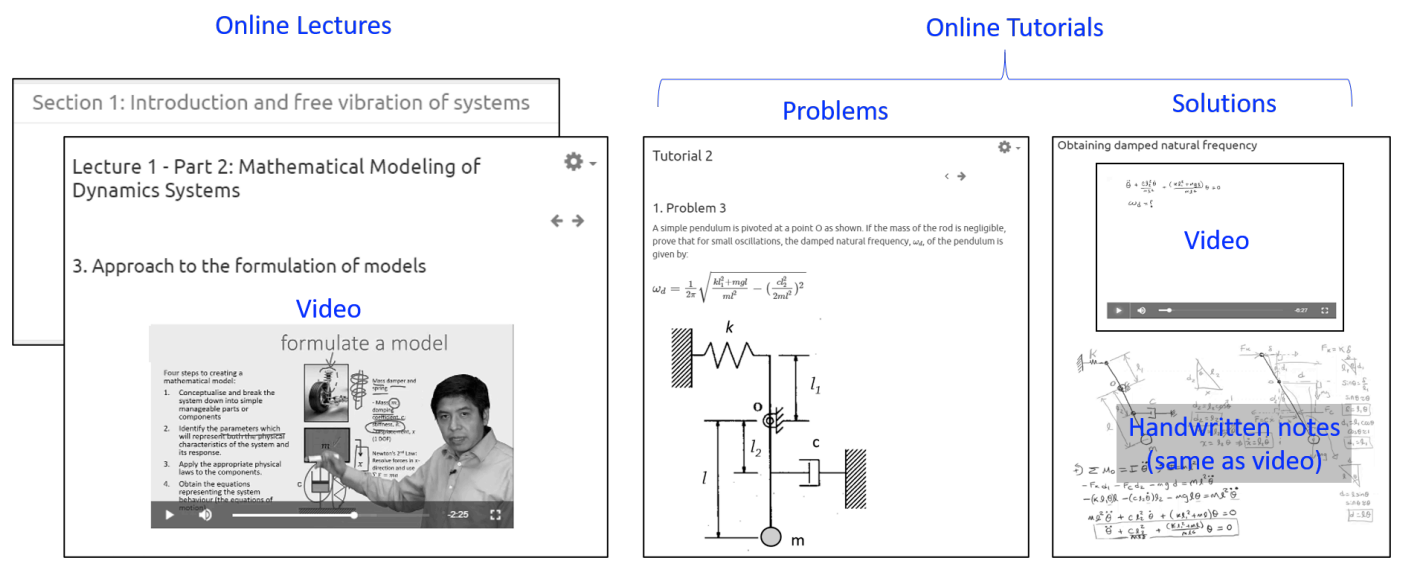

Figure 2: Sample of Online Resources

In this pilot run, we created video recordings of lectures nested within PowerPoint slides (Figure 2), PowerPoint slides with audio recordings, and step-by-step problem-based tutorials with audio recordings. These videos were created in addition to standard F2F teaching on these topics. Students were invited to view these resources and we administered questionnaires to identify, which aspects of online and F2F learning contributed to their learning. The goal of this pilot was to determine aspects of the course best suited for conversion to online videos that would be made available on the LMS platform. We also wanted to identify the quantity of online video content that would be manageable for a typical semester.

\section{Questionnaire Survey:}

Q1. Which type of teaching F2F format is more effective in your learning?

Q2. Which type of video does contribute more to your learning?

Q3. How many videos are sufficient for a 12-week course?

Q4. Which one of the following online material structure formats do you find more engaging?

Q5. Do you find the need for discussing material with someone?

The questionnaire survey was conducted using Google Forms and restricted to students from our programme. The survey itself was anonymous and students across four engineering programmes were invited to participate. All students were studying the second trimester of the first year in 2020. Eighty-eight students responded and the results are reported in the next section.

\section{Student Engagement Model}

To identify what indicators (ways to measure) and facilitators (aspects of online material) enhance engagement, we use a modified version of the model proposed in (Manwaring et al., 
2017). The model by Manwaring et al., (2017) has three categories of engagement facilitators:

1. Individual level (student) represents the type of personal qualities that students bring to instructional experiences. We relate this facilitator to the physiological need of "Competence". This facilitator measures individual confidence, which is related to the need to produce desired outcomes and to experience mastery.

2. Institutional design (instructor) represents the course design elements the instructor brings to the learning experience, e.g., the number of choice students had in the learning activity. This facilitator is related to the psychological need of "Autonomy", e.g., in our study is related to the choice provided how the online material is organised.

3. Student perception measures how the student is experiencing the learning activity. One of the characteristics of this category is related to the psychological need of "Relatedness". In our study, we relate this to the need to feel connected to others.

The modified model for this study is depicted in Figure 3. Table 1 shows the list of the questions we proposed that associated with the facilitators.

Facilitators

Indicators

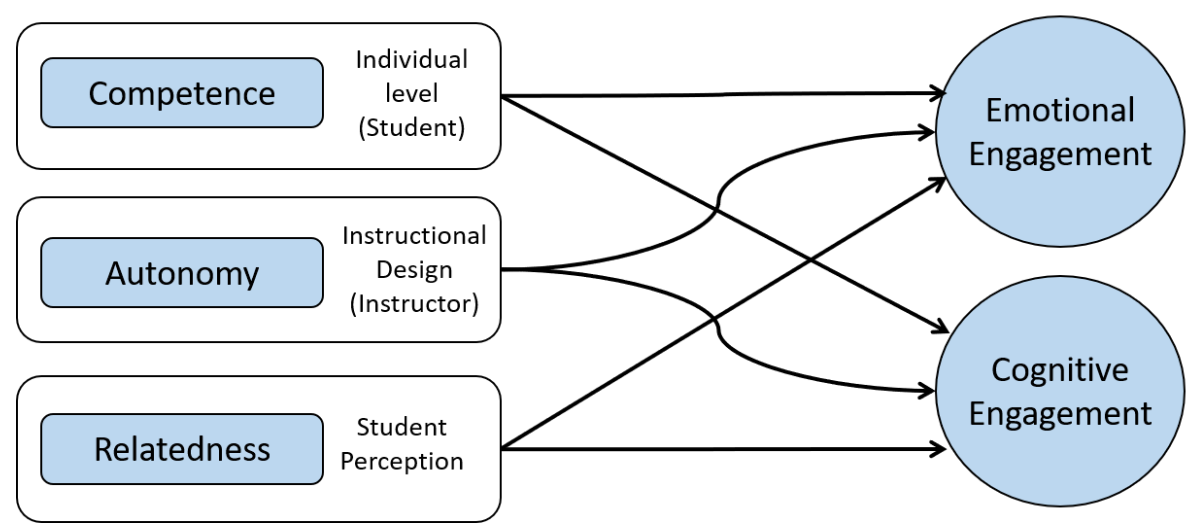

Figure 3: Modified Version of the Student Engagement Model by Manwaring Et Al., (2017).

Table 1: Facilitators and Questions of the Modified Student Engagement Model.

\begin{tabular}{|l|l|}
\hline Facilitators & Question \\
\hline Competence & Q1, "Which type of teaching F2F format is more effective in your \\
& learning?” \\
& Q2 Which type of video does contribute more to your learning? \\
\hline Autonomy & Q3 How many videos are sufficient for a 12-week course? \\
& Q4 Which one of the following online material structure formats do you \\
& find more engaging? \\
\hline Relatedness & Q5 Do you find the need for discussing material with someone? \\
\hline
\end{tabular}

\section{Results}

Figure 4 shows the responses to question Q1, "Which type of teaching F2F format is more effective in your learning?"

Overwhelming majority of students identified problem-based tutorials as the most effective format for face-to-face teaching. The second best option that they identified was didactic lectures. 


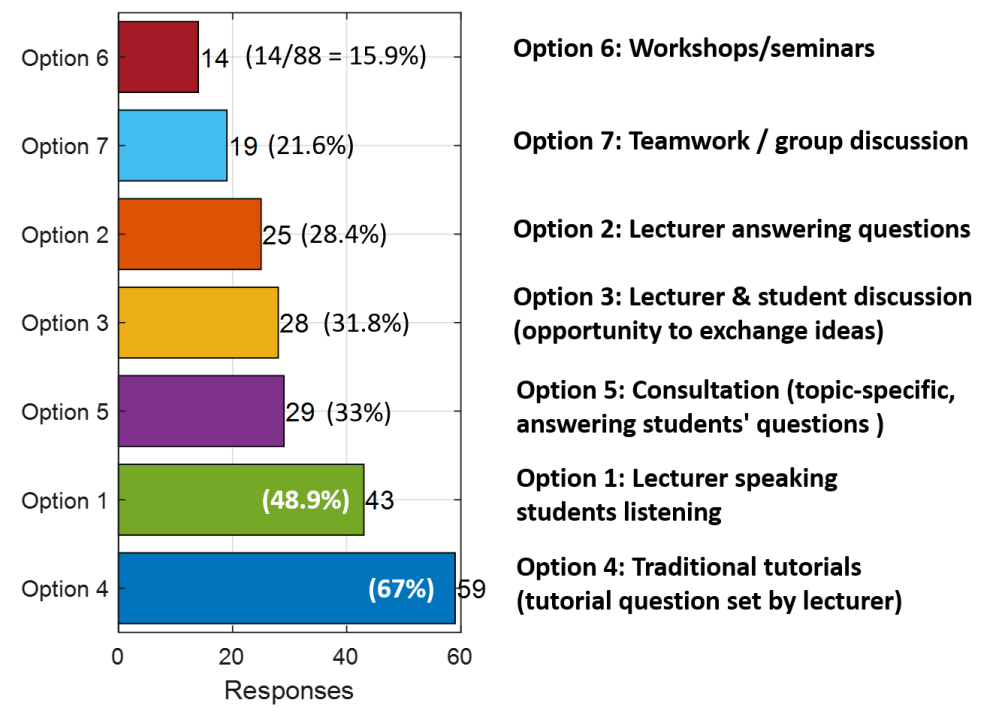

Figure 4: Q1 Which Type of Teaching F2F Format Is More Effective in Your Learning?

Figure 5 shows that $89.5 \%$ of the students find that recordings of problem-solving tutorials contributed to their learning. Video recordings of the solution were slightly preferred in comparison with audio recordings over power point. On the contrary, from a student's perspective, videos of lectures or videos of supplementary lectures have the least contribution to their learning.

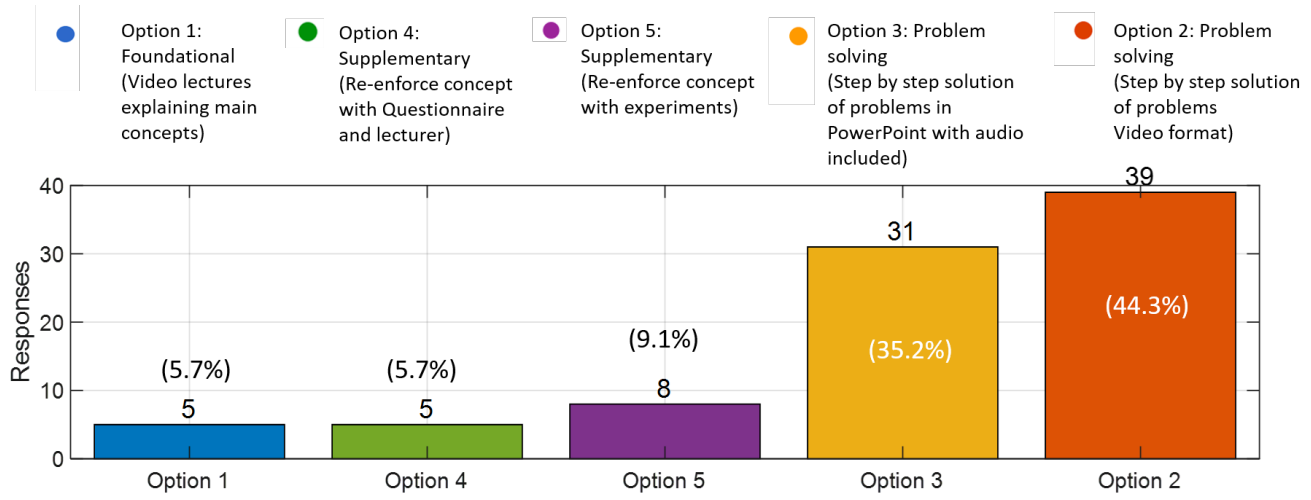

Figure 5: Q3 Which Type of Video Does Contribute More to Your Learning?

Figure 6 shows that $52.3 \%$ of the students consider that between 10 to 50 videos of tutorials or lectures are sufficient for a 12-week course.

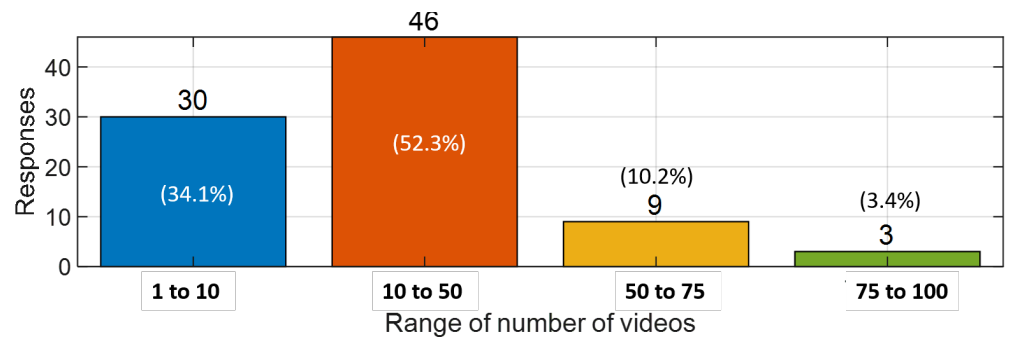

Figure 6: Q2 How Many Videos Are Sufficient for a 12-Week Course? 
In Figure 7, from the student's perspective, it can be seen that $45.5 \%$ prefer that online material is organised in week-by-week sections.

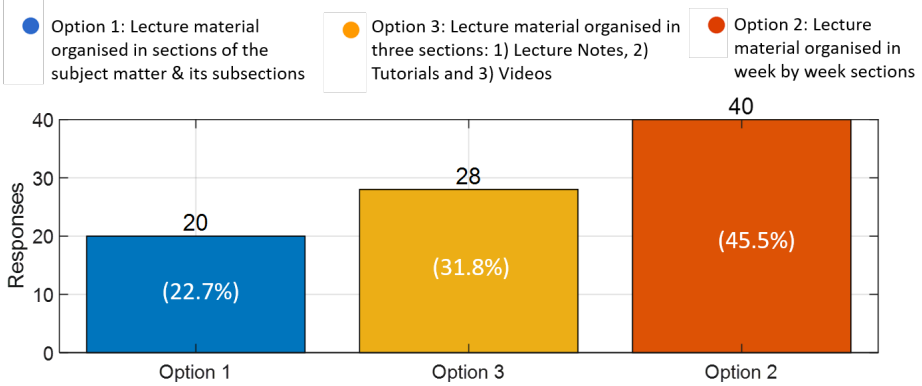

Figure 7: Q4 Which One of the Following Online Material Structure Formats Do You Find More Engaging?

In Figure 8 , students responded that $65.9 \%$ of them needed to discuss the material with their classmates, and almost $30 \%$ needed to discuss the material with the lecturer, highlighting the need for incorporating opportunities for dialogue with lecturers and colleagues.

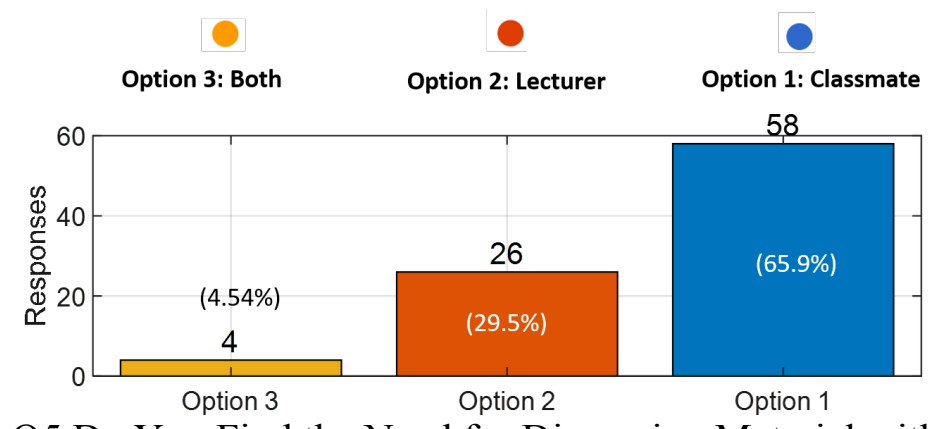

Figure 8: Q5 Do You Find the Need for Discussing Material with Someone?

\section{Discussion}

After examining the response to the questionnaire or the learners' preferences, we identify that the students perceive both F2F and recording of problem-solving as contributors to their learning. We interpret this as a facilitator to provide students with the opportunity to fulfil the need to produce desired outcomes and to experience mastery (Competence). Online lectures by comparison are least preferred by students as the platform for learning and hence would be least suited to conversion to online learning. Interestingly, students rated F2F didactic lectures more favourably (Figure 4). Students responded that online material organised in week-by-week section with 10 to 50 videos of tutorials or lectures. Finally, students expressed the need to discuss coursework both with lecturers and other classmates, which could serve both as the means to achieving competence, and the psychological need to be connected to others (relatedness). Online platforms have the potential to facilitate this interaction and suggest more effort be channelled towards the creation of resources that allow students and lecturers to communicate. The findings and their relationship to the modified student engagement model (Figure 3) are summarised in Table 2 below. 
Table 2: Summary of Results

\begin{tabular}{|l|l|l|}
\hline Facilitator & Question & Response with majority \\
\hline Competence & $\begin{array}{l}\text { Q1, "Which type of teaching F2F } \\
\text { format is more effective in your } \\
\text { learning?" } \\
\text { Q2 Which type of video does } \\
\text { contribute more to your learning? }\end{array}$ & $\begin{array}{l}\text { F2F Problem-based tutorials and } \\
\text { Recordings of problem-solving tutorials } \\
\text { contribute to their learning followed by } \\
\text { didactic lecturing. }\end{array}$ \\
\hline Autonomy & $\begin{array}{l}\text { Q3 How many videos are } \\
\text { sufficient for a 12-week course? } \\
\text { Q4 Which one of the following } \\
\text { online material structure formats } \\
\text { do you find more engaging? }\end{array}$ & $\begin{array}{l}\text { Between 10 to 50 videos of tutorials or } \\
\text { lectures are sufficient for a 12-week } \\
\text { course. } \\
\text { Online material organised in Week-by- } \\
\text { week sections. }\end{array}$ \\
\hline Relatedness & $\begin{array}{l}\text { Q5 Do you find the need for } \\
\text { discussing material with someone? }\end{array}$ & $\begin{array}{l}\text { The majority finds the need to discuss } \\
\text { the material with classmates followed } \\
\text { by the need to discuss it with the } \\
\text { Lecturer. }\end{array}$ \\
\hline
\end{tabular}

These preliminary results identified some potential facilitators and will provide guidance for further research on identifying more facilitators or learners' preferences that are best received through online sources.

Limitations to this approach include the caveat the students' perception of the utility of each mode of teaching (e.g., lectures versus seminars) may not directly compare with the actual utility. For example, students who do not prefer to go to a workshop, or to a group discussion, they may still learn important skills and gain insight from the session that contributes to their cognitive engagement overall. This aspect of learning needs to be explored with serial questionnaires and performance indices in future work. The relatedness facilitator (social processed) identified in this work needs further investigation, as pointed out by Manwaring et al., (2017), it has potential to impact in both cognitive and emotional engagement. In this work, based on previous research mentioned in the introduction, we assume that the facilitators investigated here (Table 2) have an impact on student engagement. However, to find the correlations between facilitators and student engagement indicators, statistical validation needs to be conducted in future research.

\section{Conclusion}

The results presented here suggest that when designing blended courses, problem-based tutorials are preferred by students in comparison with didactic lectures. Our findings identify recorded video tutorials in combination with F2F lectures as a powerful tool to enhance student satisfaction and engagement.

Future work will address the limitations of the current approach. It is worth mentioning that this research is a pilot study and we have presented preliminary results only, the intent is to re-evaluate the approach to further identify more learners' preferences (facilitators) that impact student engagement in online and blended learning environments. 


\section{References}

Coates, H. (2005a). Leveraging LMSs to Enhance Campus-Based Student Engagement. Educause Quarterly, 28, 66-68.

Coates, H. (2005b). The value of student engagement for higher education quality assurance. Quality in Higher Education, 11(1), 25-36. https://doi.org/10.1080/13538320500074915

Deci, E. L., \& Ryan, R. M. (1985). Cognitive evaluation theory. In Intrinsic motivation and self-determination in human behavior (pp. 43-85). Springer.

Deci, E. L., \& Ryan, R. M. (1994). Promoting Self-determined Education. Scandinavian Journal of Educational Research, 38(1), 3-14. https://doi.org/10.1080/0031383940380101

Delialioğlu, Ö. (2012). Student Engagement in Blended Learning Environments with Lecture-Based and Problem-Based Instructional Approaches. Journal of Educational Technology \& Society, 15(3), 310-322.

http://www.jstor.org/stable/jeductechsoci.15.3.310

Fredricks, J. A., Blumenfeld, P. C., \& Paris, A. H. (2004). School engagement: Potential of the concept, state of the evidence. Review of Educational Research, 74(1), 59-109.

Garrison, D. R., \& Kanuka, H. (2004). Blended learning: Uncovering its transformative potential in higher education. The Internet and Higher Education, 7(2), 95-105. https://doi.org/https://doi.org/10.1016/j.iheduc.2004.02.001

Graham, C. R., Woodfield, W., \& Harrison, J. B. (2013). A framework for institutional adoption and implementation of blended learning in higher education. The Internet and Higher Education, 18, 4-14. https://doi.org/https://doi.org/10.1016/j.iheduc.2012.09.003

Manwaring, K. C., Larsen, R., Graham, C. R., Henrie, C. R., \& Halverson, L. R. (2017). Investigating student engagement in blended learning settings using experience sampling and structural equation modeling. The Internet and Higher Education, 35, 21-33. https://doi.org/10.1016/J.IHEDUC.2017.06.002

Park, S., Holloway, S. D., Arendtsz, A., Bempechat, J., \& Li, J. (2012). What Makes Students Engaged in Learning? A Time-Use Study of Within- and Between-Individual Predictors of Emotional Engagement in Low-Performing High Schools. Journal of Youth and Adolescence, 41(3), 390-401. https://doi.org/10.1007/s10964-011-9738-3

Raes, A., \& Depaepe, F. (2020). A longitudinal study to understand students' acceptance of technological reform. When experiences exceed expectations. Education and Information Technologies, 25(1), 533-552. https://doi.org/10.1007/s10639-01909975-3 
Sun, J. C.-Y., \& Rueda, R. (2012). Situational interest, computer self-efficacy and selfregulation: Their impact on student engagement in distance education. British Journal of Educational Technology, 43(2), 191-204.

https://doi.org/https://doi.org/10.1111/j.1467-8535.2010.01157.x

Contact email: arturo.molina-cristobal@glasgow.ac.uk 


(C) The International Academic Forum 2021 The International Academic Forum (IAFOR)

Sakae |-|6-26-20|

Naka Ward, Nagoya, Aichi

Japan 460-0008

www.iafor.org 